\title{
RESENHA
}

\section{SILVA, AYALLA OLIVEIRA. ORDEM IMPERIAL E ALDEAMENTO INDÍGENA: CAMACÃS, GUERÉNS E PATAXÓS NO SUL DA BAHIA. ILHÉUS: EDITUS, 2018.}

\author{
Por Renata Ferreira de Oliveira *
}

Por muito tempo, a história relegou aos índios um lugar estritamente demarcado pela passividade ou condição de vítima. Os povos indígenas foram concebidos pela historiografia a partir de categorias genéricas, que invisibilizaram as inúmeras diferenças étnicas e culturais. Lidos como incapazes de agir diante das suas realidades, a tendência de análise era a do desaparecimento ante uma sociedade em expansão. Todavia, nas últimas duas décadas, é possível afirmar que essa condição dos índios na historiografia brasileira mudou a partir da emergência da denominada "nova história indígena" que, por meio de significativas mudanças teóricas, metodológicas e empíricas, redimensionou o papel dos índios na história, dotando-os de protagonismo.

No que tange ao surgimento desse novo campo de abordagem da história dos nativos brasileiros, dois pontos merecem destaque pelo papel significativo que desempenharam no processo de mudança. O primeiro é a aproximação entre História e Antropologia. Esse diálogo interdisciplinar, visto com uma tendência mais forte nos fins da década de 1970, incidiu significativamente sobre essa nova perspectiva, possibilitando renovados pressupostos teórico-metodológicos para as duas áreas, que expandiram expressivamente os horizontes de pesquisas. O segundo ponto versa sobre a questão indígena na contemporaneidade. O crescimento demográfico das populações nativas e as retomadas étnicas observadas, sobretudo a partir da segunda metade do século XX, desmistificaram o discurso de desaparecimento e extinção de inúmeros povos indígenas. Aliado a esse fator o movimento de retomada étnica pressupunha também a retomada dos territórios tradicionais indígenas, seja de seus aldeamentos missionários ou de suas aldeias tradicionais. Isso, consequentemente, levou a novas observações sobre o passado desses povos, pensadas, agora, a partir de uma demanda do presente.

É dentro desse novo aparato historiográfico sobre os índios do Brasil, que se insere o livro Ordem Imperial e Aldeamento Indígena: Camacãs, Gueréns e Pataxós no sul da Babia, da autora Ayalla Oliveira Silva. A obra, lançada em 2018, pela Editus - Editora da Universidade Estadual de Santa Cruz - trata

\footnotetext{
* Professora do Instituto Federal de Ciência e Tecnologia do Norte de Minas Gerais (IFNMG). Doutoranda em História pela Universidade Federal da Bahia (UFBA).E-mail: renataconquista@gmail.com
} 
da história da formação da cidade de Itabuna no sul da Bahia, porém o faz sob a perspectiva da participação dos índios como agentes da construção dessa história.

O livro é o resultado da dissertação de mestrado da autora. O intuito da pesquisa foi localizar os índios do antigo aldeamento de São Pedro de Alcântara, conhecido por Ferradas, e destacar sua importância para a formação da atual cidade de Itabuna, em uma perspectiva capaz de dialogar com as produções dessa nova historiografia sobre os índios, conectando-os com a realidade da política indigenista colonial e imperial para demonstrar que o aldeamento de Ferradas não estava apartado da questão indígena nacional.

Ayalla Silva inicia a obra com uma revisão historiográfica, começando com o texto de John Monteiro (2001), cuja pesquisa é marco para entendermos os índios como pessoas capazes de desempenhar um papel ativo e criativo nas conjunturas que estavam imersos. É o denominado "índio colonial", que se tornou ator histórico a partir da emergência das novas abordagens, como já dito acima. Ainda na sessão introdutória, Ayalla Silva visita outros autores que, assim como Monteiro, são precursores de uma nova história indígena, a exemplo de João Pacheco de Oliveira (1998), Maria Regina Celestino Almeida (2013), Maria Hilda Baqueiro Paraíso (2014), dentre outros.

Articulando o cenário nacional com o local, a autora localiza-se dentro do panorama de produção historiográfica baiana, cujos estudos indígenas são tímidos. Para o sul da Bahia, essa produção é ainda mais reduzida. Nesse sentido, Ordem Imperial e Aldeamento Indígena contribui significativamente para tornar a história da Bahia e da região sul do estado também uma história dos índios. O intuito de Ayalla Silva é desvendar as práticas empreendedoras da colonização e a atuação dos índios frente a essas práticas, no contexto do século XIX, em Itabuna, refletindo acerca do funcionamento das políticas administrativas indigenistas, que aldeavam e exploravam o trabalho indígena; em contraponto, a autora busca entender as agências dos índios de Ferradas e pensá-los "como atores de sua trajetória histórica no mundo da colonização oitocentista no sul da Bahia" (p. 28).

O primeiro capítulo do livro é uma antessala de discussão da temática indígena na história da cidade de Itabuna. Nesse espaço, a autora faz uma interpretação da história do sul da Bahia a partir da inserção dos índios como agentes em contextos complexos de interação com não índios. Por muito tempo, a memória sobre a cidade de Itabuna versava apenas sobre o legado da imigração sergipana no contexto de desenvolvimento da economia cacaueira e da formação de uma elite econômica (p. 37). As bases para a edificação da história itabunense foram estabelecidas por meio de uma narrativa hegemônica, que entrelaçou história e política, tendo a imprensa como grande difusora. Dessa maneira, a história da cidade, contada por meio de seus memorialistas, destacava a importância dos novos ricos e o progresso associado ao cacau; ou seja, as disputas pela memória do passado desse lugar estabeleceram-se porque era imperioso para os representantes políticos do século XX narrar 
uma história que serviria como instrumento político da elite cacaueira. E foi assim que os imigrantes sergipanos foram eleitos como protagonistas.

E qual era o lugar dos índios de Ferradas nesse processo? É tentando responder a essa pergunta que Ayalla Silva tece uma nova história para a cidade de Itabuna. Revisitando os arquivos de sua cidade, bem como trazendo à baila documentos da Província da Bahia que tratavam especificamente dos índios, a autora demonstra que a invisibilidade dos indígenas de Ferradas nas páginas da história de Itabuna foi proposital, pois eles sempre estiveram inseridos no processo de formação dos núcleos populacionais que geraram a cidade, além de serem mão de obra de extrema relevância para trabalhos ligados ao Estado e a particulares: "Os índios aldeados de Ferradas, que atuaram indireta ou diretamente na lavoura do cacau, possibilitaram o acesso de colonos à região, bem como empregaram a sua mão de obra nas roças de cacau, durante o século XIX” (p. 65).

No segundo capítulo, Ayalla Silva trata especificamente do Aldeamento de Ferradas. O contexto de criação desse aldeamento é marcado por uma massiva ideia de colonização e progresso das regiões de fronteiras agrícolas desencadeados a partir da crise nas zonas mineradoras (PARAÍSO, 2013). Para o sul da Bahia, o projeto de aberturas de estradas para a integração com os sertões esbarrava na presença indígena não aldeada e na falta de mão de obra, ao passo que a política indigenista do período valorizava o trabalho indígena no processo de colonização, mas, também, visava a apropriação do território indígena e a segurança dos colonos (p. 92).

Com o intuito de discutir a territorialização do aldeamento de Ferradas, Ayalla Silva retoma o conceito de territorialização tomado de empréstimo de João Pacheco de Oliveira, que o define como um ato político realizado por um grupo de pessoas, em um determinado espaço geográfico, que compartilham laços étnicos e se colocam como agentes de suas atitudes e interesses (OLIVEIRA, 1998, p. 54). Para a autora, o conceito pode ser muito bem aplicado ao território dos índios Camacãs, Pataxós e Gueréns se pensarmos que esses, como aldeados, estavam imersos em um contexto de diversas relações coloniais, mas que "foram capazes de reconfigurar as suas vidas na realidade colonial" (p. 94).

A autora diz que a fundação do aldeamento de Ferradas precisa ser compreendida a partir da perspectiva da política indigenista da virada do século XVIII para o XIX, cujo intuito era atender à demanda colonial por território e trabalho. Além disso, baseada na documentação sobre o aldeamento, Ayalla Silva informa que esse estabelecimento era importante porque poderia funcionar como "apoio para a formação ou manutenção de outros aldeamentos, pois os indígenas circulavam de forma itinerante pela região" (p. 137). Ou seja, o lugar de trânsito dos indígenas era bastante superior ao território do aldeamento. Os padres, administradores, também detinham um papel importante nesse aspecto.

A autora argumenta que, em Ferradas, o frei responsável pelo aldeamento dos índios estabeleceu uma teia de comunicação entre diferentes espaços que circundavam o aldeamento. Isso 
pode ser lido de duas formas. Primeiro, como uma forma de locomover os índios para o trabalho em empreendimentos regionais; segundo, para utilizá-los como pacificadores e força de atração de índios não aldeados. Por fim, Ayalla Silva retoma a ideia de territorialidade para explicar esse complexo mundo indígena dentro e fora do aldeamento, uma vez que os índios circulavam entre o centro administrativo do aldeamento e as aldeias afastadas, bem como conviviam com outros índios, a exemplo dos Pataxós não aldeados, em um processo contínuo de ressignificação de seus territórios (p. 142).

O terceiro capítulo dedica-se à territorialização e ao trabalho dos índios de Ferradas. É importante destacar que o aldeamento também funcionava como um espaço de inserção dos índios na sociedade. Nesse sentido, Maria Regina Celestino Almeida argumenta que os aldeamentos de índios no Brasil também podem ser entendidos como espaços de interesses dos índios, que "participaram de sua construção e foram sujeitos ativos dos processos de ressocialização e catequese" ALMEIDA, 2010, p. 72). No caso do aldeamento de Ferradas, Ayalla Silva argumenta que o trabalho dos índios foi largamente utilizado nos serviços públicos e particulares. Eles eram empregados nos estabelecimentos de pequenos colonos e grandes fazendeiros e na abertura da estrada que ligava as vilas de Ilhéus a Vitória da Conquista. (p. 149)

A partir da análise das fontes, a autora demonstra que os índios de São Pedro de Alcântara desempenharam um papel primordial na abertura da estrada que ligava o litoral (Ilhéus) ao sertão (Vitória da Conquista), estrada importante para o desenvolvimento econômico da região e expansão de fronteiras. Além disso, o aldeamento tinha um outro propósito nessa trama: manter a estrada Ilhéus-Vitória da Conquista, garantindo a segurança dos viajantes e dos colonos que pretendiam se estabelecer na região. Por outro lado, a autora localiza os índios como trabalhadores da lavoura de cacau ainda nos seus primórdios. Dentro do contexto da política indigenista imperial, o trabalho dos índios facilitava o sucesso da colonização e foi o meio pelo qual eles se integraram, como nacionais, à sociedade. Conforme argumenta a autora, “o sucesso do projeto colonizador na região de Ferradas estava condicionado à assimilação dos Camacãs, Pataxós e dos Guerens ao processo de catequese nos aldeamentos" porque era dessa maneira que os propósitos imperiais relativos à questão fundiária lograriam êxito (p. 173).

Ainda nessa parte do livro, a autora discute o trabalho indígena no contexto da formação da lavoura de cacau e coloca os índios no centro das reconfigurações que a região adquiriu com a chegada desse cultivo. Ao analisar as falas do presidente da província à época, Ayalla Silva consegue atestar que o aldeamento participou ativamente da lavoura do cacau como produtor de importância significativa, pois, em um dado momento, havia mais de vinte mil pés de café e vinte mil pés de cacau plantados pelos índios nesse espaço (p. 199). Isso significa dizer que os índios estavam inseridos em uma economia de aldeamento que os conectava ao contexto de desenvolvimento regional. 
Preocupada em dar visibilidade aos indígenas de Ferradas a partir do que se convencionou chamar de agências, Ayalla Silva elabora o quarto capítulo do livro sob a premissa de que os índios habitantes do sul da Bahia participaram ativamente do processo de colonização, dinamizando-o. Nas palavras da autora: “o processo deve ser observado enquanto uma teia, um emaranhado de conflitos e negociações, resultantes do encontro dos diferentes atores e grupos sociais naquela época” (p. 205). Lançando mão dos conceitos de etnogênese e ressocialização, cunhados respectivamente por John Monteiro e Maria Regina Celestino Almeida, Ayalla Silva analisa a documentação produzida pelos padres capuchinhos referente a Ferradas.

A reflexão da autora, a partir dos relatos documentais que evidenciam um universo violento no qual estavam envolvidos aldeados e não aldeados, leva a pensar a ação dos índios botocudos "para além da ideia engessada da existência de uma fronteira rígida entre colonizadores e índios” (p. 219). Nesse sentido, Ayalla Silva propõe que as realidades de contato formaram um imbricado processo que funcionou de ambos os lados por meio de negociações.

Dessa maneira, a autora opera com o conceito de negociação no sentido de apontar as tomadas de decisões dos índios frente ao avanço do mundo colonial como ações conscientes e de interesse dos próprios índios. Nas suas palavras, “os Botocudos e Pataxós do sul da Bahia agiam conscientes dos limites que lhes eram impostos. Eles sabiam a hora de resistir conflitivamente, mas também se adaptavam à condição colonial quando necessário” (p. 220).

Esse é o ponto de argumentação mais complexo do livro. A violência vivida cotidianamente pelos índios precisa ser problematizada, de forma a não torná-los passivos, assim como faz a autora, mas também necessita ser dimensionada e demonstrada, no sentido de apontar a perdas sofrida pelos índios desde os primeiros contatos com os colonos, a partir de um sistema organizado que visava, por meios violentos, obter terras e mão de obra. ${ }^{1}$

A resistência/ressignificação da identidade indígena nos contextos de aldeamentos e interação étnica com os não índios ou mesmo com etnias diferentes também é um ponto complexo de análise porque os indígenas lutaram de infinitas maneiras pela sobrevivência, mas em uma conjuntura de tensão. Essa resistência é tensa e conflitiva, uma vez que a perda das terras das aldeias e a redução nos aldeamentos missionários inauguraram para os indígenas um estado de guerra que terminou por lançá-los impiedosamente em uma sociedade desejosa de seu desaparecimento. A extinção do aldeamento de Ferradas, tema do quinto capítulo do livro, demonstra que, apesar da resistência imposta pelas etnias indígenas do sul da Bahia, prevaleceu o objetivo da política indigenista imperial da segunda metade do século XIX.

\footnotetext{
${ }^{1}$ Há vários trabalhos escritos dentro dessa perspectiva, a exemplo da dissertação de mestrado escrita por um índio do médio Xingu, William César Lopes Domingues. Nela, o autor se propõe a discorrer, a partir da visão indígena, sobre a construção da Usina de Belo Monte e sobre como esse empreendimento foi uma cascata de violência para os povos indígenas atingidos. $\mathrm{O}$ autor discorre, ainda, sobre a onda de violência que assolou o mundo indígena desde os primeiros contatos coloniais (Cf. DOMINGUES, 2017).
} 
Um exemplo desse argumento que levanto, e que pode ser visto na documentação utilizada pela autora, é a petição dos índios Botocudos canoeiros do Rio Pardo, quando dizem que são moradores das margens desse rio e que desejam se reunir em sua primitiva terra e formar a aldeia que seria sustentada com o trabalho de seus braços na canoagem, tão importante para o dito rio (p. 183)

Os índios, acessando o universo colonial, não estão negociando a estadia em determinado espaço geográfico, como argumenta a autora; ao contrário, estão afirmando serem eles os legítimos donos daquela terra e imprescindíveis para o comércio com canoas no rio, e por isso desejam estabelecer a aldeia no local mais apropriado para eles. Com isso, não estou negando as agências indígenas, tão bem demonstradas por Ayalla Silva, estou problematizando-as no sentido de pensar até que ponto as negociações foram capazes de garantir, ainda que momentaneamente, a integridade do território e da vida dos indígenas do sul da Bahia diante de um projeto de Estado cujo intuito era atingir o progresso e a civilização tão sonhados no século XIX, e que, consequentemente, esbarrava nas terras indígenas. A extinção do aldeamento de Ferradas e o desaparecimento dos índios da documentação, como aponta a autora no quinto capítulo do livro, têm muito a nos dizer sobre isso.

Por fim, o quinto e último capítulo é dedicado a pensar a extinção do aldeamento de Ferradas e a fundação de uma colônia agrícola em suas terras, na segunda metade do século XIX. A ação do governo provincial dedicada a extinguir o aldeamento é intrigante pois, como demonstrado pela autora, os índios permaneciam ativos no mundo do trabalho, seja na estrada Ilhéus-Conquista, seja nas lavouras. Na prática, o que teria significado o desaparecimento do aldeamento e, também, dos aldeados? Ayalla Silva fornece algumas pistas: “a atuação de uma política de colonização agrícola subsidiada por uma política indigenista de fins do Oitocentos, no sul da Bahia, tinha como fim premeditado invisibilizar etnicamente os índios a exemplo dos de Ferradas" (p. 293). Isso pode sugerir que, à medida que desaparecia propositalmente a categoria jurídica de "índios" e surgia a de trabalhadores, a política de tutela do Estado perdia sentido.

À guisa de conclusão, cabe dizer que Ordem Imperial e Aldeamento Indígena é uma obra de extrema relevância para o estudo das populações indígenas da Bahia e, especificamente, da parte sul do Estado. O livro nos oportuniza conhecer a trajetória de pessoas submetidas a um mundo de violência colonial, cuja marca pode ser vista ainda hoje nas aldeias dessa região. A obra também é um instrumento político de afirmação da resistência e da presença indígena na região, bem como uma possibilidade de repensar o papel dos índios na formação étnica/cultural e econômica da Bahia.

\section{REFERÊNCIAS}

ALMEIDA, M. R. C. de. Metamorfoses indígenas: identidade e cultura nas aldeias coloniais do Rio de Janeiro. 2 ed. Rio de Janeiro: Ed. da FGV, 2013.

ALMEIDA, M. R. C. de. Os indios na história do Brasil. Rio de Janeiro: Ed. da FGV, 2010. 
DOMINGUES, W. C. L. Cachaça, concreto e sangue! Saúde, alcoolismo e violência: povos indígenas no contexto da Hidrelétrica de Belo Monte. 2017. Dissertação (Mestrado em Antropologia) Universidade Federal do Pará, Belém, 2017.

MONTEIRO, J. M. Tupis, tapuias e historiadores: estudos de história indígena e do indigenismo. 2001. Tese (Livre docência) - Universidade Estadual de Campinas, Instituto de Filosofia e Ciências Humanas, Campinas, 2001.

OLIVEIRA, J. P. de. Uma etnologia dos índios misturados? Situação colonial, territorialização e fluxos culturais. Mana., Rio de Janeiro, v. 4, n. 1, p. 47-77, abr. 1998.

PARAÍSO, M. H. B. O tempo da dor e do trabalho: a conquista dos territórios nos sertões do leste. Salvador: EDUFBA, 2014. 